\title{
Properties of Raphia Palm Interspersed Fibre Filled High Density Polyethylene
}

\author{
Henry C. Obasi \\ Department of Polymer and Textile Engineering, Federal University of Technology, Owerri, P.M.B. 1526, Owerri, Imo State, Nigeria \\ Correspondence should be addressed to Henry C. Obasi; neduobasi35@yahoo.com
}

Received 29 May 2013; Accepted 1 October 2013

Academic Editor: Wen-Hua Sun

Copyright (C) 2013 Henry C. Obasi. This is an open access article distributed under the Creative Commons Attribution License, which permits unrestricted use, distribution, and reproduction in any medium, provided the original work is properly cited.

\begin{abstract}
Blends of nonbiodegradable and biodegradable polymers can promote a reduction in the volume of plastic waste when they undergo partial degradation. In this study, properties of raphia palm interspersed fibre (RPIF) filled high density polyethylene (HDPE) have been investigated at different levels of filler loadings, 0 to $60 \mathrm{wt}$.\%. Maleic anhydride-graft polyethylene was used as a compatibilizer. Raphia palm interspersed fibre was prepared by grinding and sieved to a particle size of $150 \mu \mathrm{m}$. HDPE blends were prepared in a corotating twin screw extruder. Results showed that the tensile strength and elongation at break of the blends decreased with increase in RPI loadings and addition of MA-g-PE was found to improve these properties. However, the Young's modulus increased with increase in the amount of RPI into HDPE and compatibilization further increased the Young's modulus. The water absorption indices and weight loss for RPI/HDPE composites were found to increase with RPI loadings but were decreased on addition of MA-g-PE.
\end{abstract}

\section{Introduction}

The use of natural fibres for the reinforcement of composites has received adequate attention by both researchers and industrialists. Traditionally, natural fibres that were used as fillers for thermosets are presently becoming one of the fastest growing additives for synthetic thermoplastics. Composites obtained from natural fillers have found useful applications in several sectors such as automobile, packaging, building, and biomaterials. The advantages of natural fillers over synthetic fibres are biodegradability and renewability, low density, low cost, reduced energy consumption, and specific mechanical properties. On the contrary, the poor compatibility between natural fibres and synthetic polymer matrix, the heterogeneous dispersion of the fibres, and poor resistance moisture lead to low performance materials and thus limiting their use [1]. At present, different kinds of natural fillers have been studied for use in synthetic polymers which include hemp, jute straw, wood, flax, rice husk, wheat, bagasse, bamboo, kenaf, oil palm empty fruit bunch, sisal, coir, raphia, pineapple leaf, and banana fiber [2].

The use of natural fibres obtained from various sources in polymeric materials provides positive environmental benefits in relation to disposability and efficient utilization of these raw materials [3]. Furthermore, natural fillers offer a new window to developing nations to use their own natural resources in their composites processing industries.

Raphia palm interspersed (RPI) fibres are natural fibres seen on the trunk of raphia palm tree (Raphia farinifera) as interspersed twines and represent an environmentally friendly alternative to traditional reinforcing fibres. Conventionally, these fibrous materials have been used by the local people as domestic binding ropes and as a source of fuel. Sometimes, these materials could be abandoned and appear as agrowastes. The literature review has revealed that not much study has been carried out in this fibre for the preparation of polymer biocomposites.

Polyethylene, due to its lower melting point, availability, low cost, and easy of processing [4], is the most frequently used synthetic thermoplastic for natural fibre plastic composite production.

In spite of the drawbacks on the use of natural fibres in polymer composites, various workers are focusing their attention on effective usage of these natural fibres in place of toxic synthetic fibres in various fields [5-7]. Najafi et al. [8] 
prepared composites of saw dust with virgin and/or recycled high density polyethylene. The mechanical properties of the prepared composites were determined by the standard procedures. The results obtained showed that the mechanical properties of the samples containing recycled HDPE were similar and comparable to those made from virgin HDPE.

The initial attack on the filler by microbes in plastics that contain blends of polyethylene and natural filler results in an increase in the porosity and surface to volume ratio of the polymer blend and a consequent enhancement of its biodegradability. It has been observed that the increase in the filler content and decrease in the filler size enhanced the biodegradability of the plastic blends [9-11]. Natural filler, such as raphia palm interspersed fibre, is an example of degradable polymer that can be used as a credible alternative to hydrocarbon plastic materials. It can also represent the conversion of biopolymers to industrially useful biomass energy. In the present study, we have reported the preparation of raphia palm interspersed fibre filled high density polyethylene composites. It is our hope that the present study will bring to bear on a scientific basis the usefulness of raphia palm interspersed fibre as a filler in compounding synthetic thermoplastic polymers. The main objectives of this study were to

(i) determine the effective utilization of raphia palm interspersed fiber in the preparation of fibre filled HDPE,

(ii) study the effect of fibre loading on the various mechanical properties of the composites,

(iii) study the effect maleic anhydride-graft-polyethylene compatibilizer in the composites,

(iv) determine the biodegradability of the resulting composites.

\section{Experimental}

2.1. Materials. Raphia palm interspersed (RPI) fibre used as filler in this study was obtained from raphia palm tree (Raphia farinifera) near the bank of Otamiri River, Owerri, Imo State, Nigeria. The fibre was cut out from the tree trunk, washed thoroughly with distilled water to remove impurities, and then dried under the sun. They were subsequently crushed to fine powder and sieved to $150 \mu \mathrm{m}$ mesh size. Moisture content of the sieved RPI fibre was $1 \%$ and $2 \%$ during blending.

High density polyethylene (HDPE) pellets were obtained from Indorama Petrochemical Company, Limited, Eleme, Rivers State, Nigeria. The density of HDPE is $0.946 \mathrm{~g} / \mathrm{dm}^{3}$. Its melting temperature and melt flow index are $134^{\circ} \mathrm{C}$ and $6 \mathrm{~g} / 10 \mathrm{~min}$, respectively. In this study, maleic anhydride-graftpolyethylene (MA-g-PE) was used as compatibilizer. It is a product of Sigma-Aldrich Chemicals, Germany, and was used as received.

2.2. Sample Preparation. A laboratory size corotating twin extruder Haake, Model Rheomix CTW 100P, was used to compound RPIF and HDPE. The screw speed was $40 \mathrm{rpm}$ and temperature range varied from 130 to $150^{\circ} \mathrm{C}$. Different levels of filler loadings $(15,30,45$, and $60 \mathrm{wt} . \%)$ were used. The blends were compression moulded. This involved hot press preheating at $150^{\circ} \mathrm{C}$ for $10 \mathrm{~min}$ followed by compression for about $4 \mathrm{~min}$ at the same temperature. The samples were removed manually from the moulds after cooling to room temperature.

In another set of sample preparation, RPIF, HDPE, and MA-g-PE were measured, fed into the extruder, and processed as described above. The quantity of MA-g-PE used was 5 wt.\% based on filler content.

2.3. Tensile Properties. Tensile properties were studied according to ASTM D882 in a universal testing machine (Shimadzu Autograph Series) using the sample obtained as described above. Tensile properties were measured at room temperature, $23 \pm 5^{\circ} \mathrm{C}$, at a rate of $50 \mathrm{~mm} / \mathrm{min}$ and average values of tensile strength, elongation at break, and Young's modulus were determined.

2.4. Water Absorption Study. The blend samples of $2 \mathrm{~mm}$ thickness were dried at $180^{\circ} \mathrm{C}$ for $24 \mathrm{~h}$ and immersed in distilled water at room temperature. The water absorption was determined by weighing the samples at regular intervals. The samples were periodically removed from the water, wiped with filter paper to remove surface water, and weighed to the nearest $0.001 \mathrm{~g}$. The amount of water absorbed by the blends at room temperature was obtained by

$$
\operatorname{Mt}(\%)=\frac{A-B}{B} \times 100,
$$

where $\mathrm{Mt}$ is the amount of water absorbed at time $t, A$ is the weight after absorption, and $B$ is the weight before absorption.

2.5. Soil Burial Test. The method employed was according to that adopted by Kaur and Guatam [12]. For this purpose, $\mathrm{RPIF} / \mathrm{HDPE}$ samples with the dimensions of $25 \mathrm{~min} \times 50 \mathrm{~min}$ were buried under soil surface to a depth of $150 \mathrm{~mm}$. The $\mathrm{pH}$ and temperature of the soil were maintained at 7 and $32 \pm 5^{\circ} \mathrm{C}$, respectively. The samples were removed, washed with distilled water, and then dried in an oven at $50^{\circ} \mathrm{C}$ over night before being weighed. The test was conducted every 7 days for 70 days of soil burial.

\section{Results and Discussion}

3.1. Tensile Properties. The determination of the mechanical properties of materials such as polymer blends involves not only scientific but also technological and practical aspects [13]. Tensile test was conducted to investigate the tensile properties of both uncompatibilized and compatibilized RPIF/HDPE composites. Figures 1, 2, and 3 show the effect of the blend ratio on the tensile strength, elongation at break, and Young's modulus of the composites. It can be distinctly observed that addition of raphia palm interspersed fibre led to the increase in Young's modulus but decreased the values of the tensile strength and elongation at break for both uncompatibilized and compatibilized composites, 


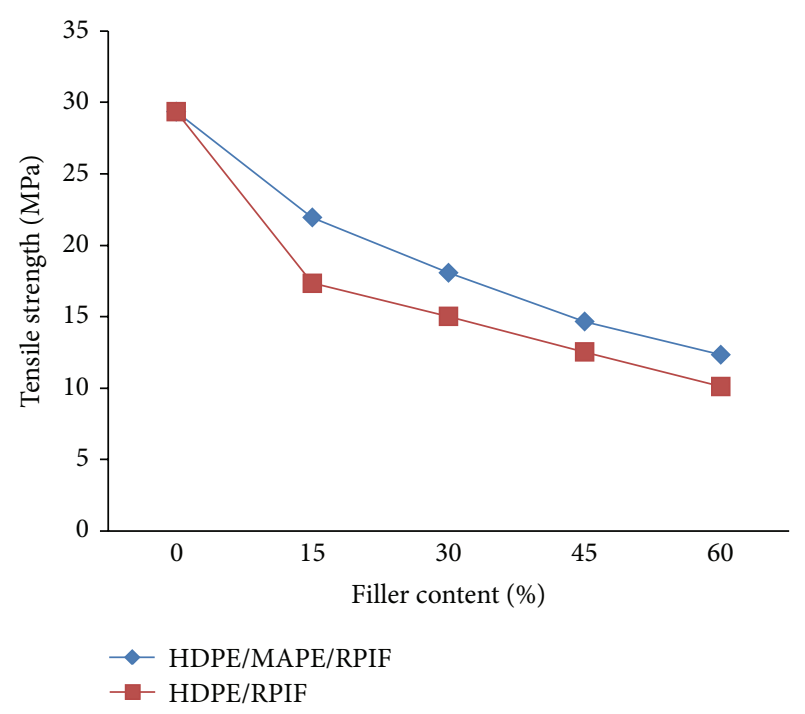

FIGURE 1: Effect of RPIF on tensile strength of RPIF/HDPE composites.

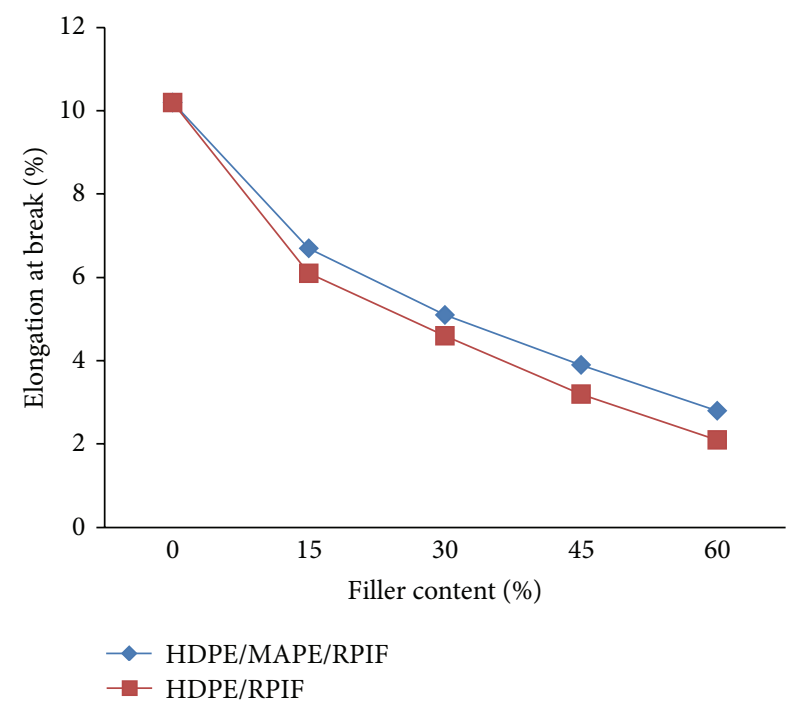

FIGURE 2: Effect of RPIF on elongation at break of RPIF/HDPE composites.

when compared with the neat HDPE. It is exciting to indicate that Young's modulus increased steadily with the incorporation of RPI fibres and may likely be caused by the rigid nature of the RPI fibres. However, the reduction in tensile strength and elongation at break was reasonably caused by a number of factors reported by [14]. The effect of compatibilizer (MA-g$\mathrm{PE}$ ) on the tensile properties of RPIF/HDPE composites was also captured as shown in Figures 1-3. It was observed that the tensile strength, elongation at break, and Young's modulus of the composites were found to increase on the introduction of MA-g-PE compatibilizer. The increase may be primarily due to improved interfacial adhesion resulting from the presence of a matrix with increased polarity that may react favourably with the hydroxyl groups on the fibre surface. This indicates

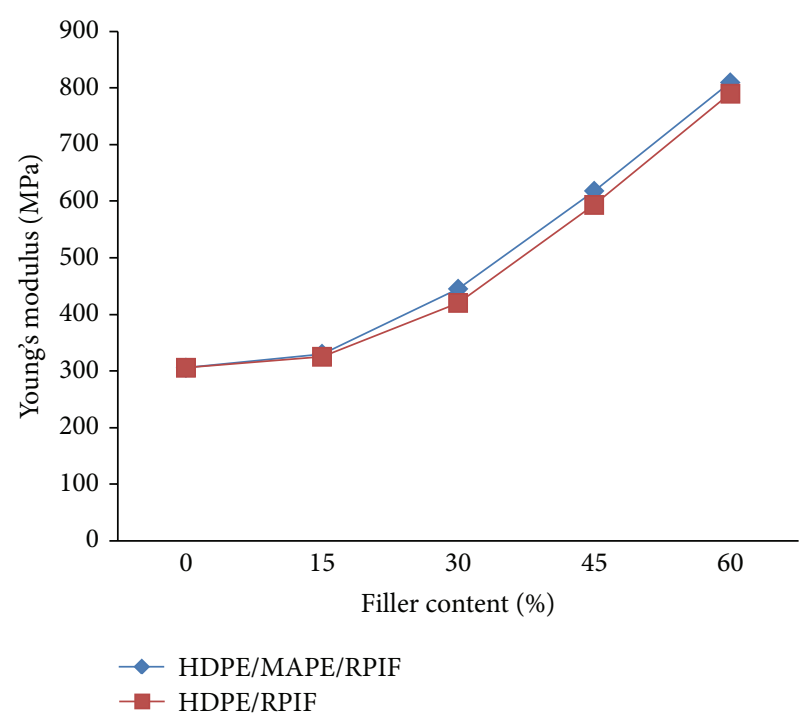

FIGURE 3: Effect of RPIF on Young's modulus of RPIF/HDPE composites.

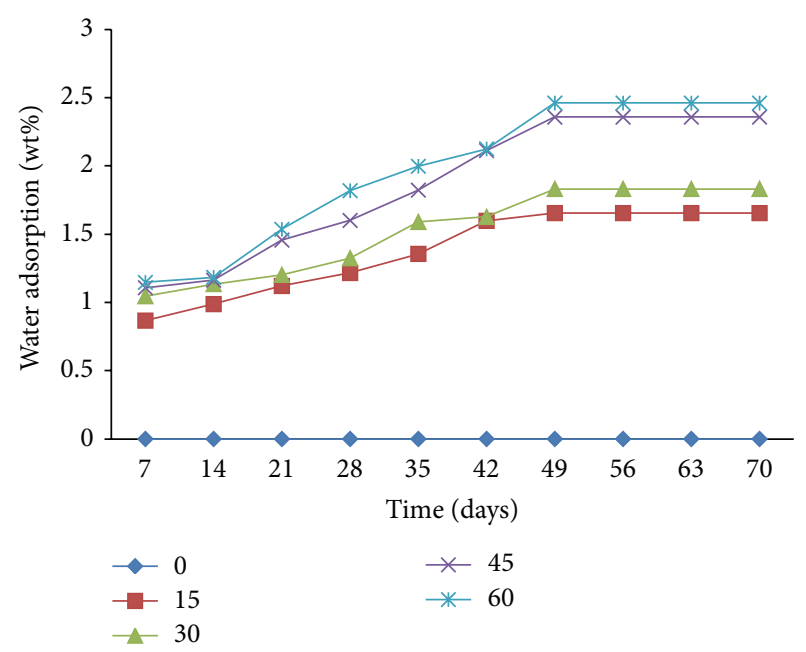

FIGURE 4: Water absorption at different RPIF loadings.

that long MA-g-PE chains formed ductile interface along with good fibre/matrix interface adhesion.

3.2. Water Absorption. The relationship between water absorption tendencies and filler content of RPIF/HDPE composites at different contents of RPIF with and without compatibilizer was illustrated in Figures 4 and 5. All the blend samples showed a similar pattern of water absorption indicating that water absorption by the blends increased with increasing immersion time and filler content. This investigation is due to the hydrophilicity of biofillers, which is responsible for the water absorption in the blends. It is interesting to note that fillers absorb water by forming hydrogen bonding between water on the cell wall of the filler. Therefore, at higher filler content, higher amount of water is 


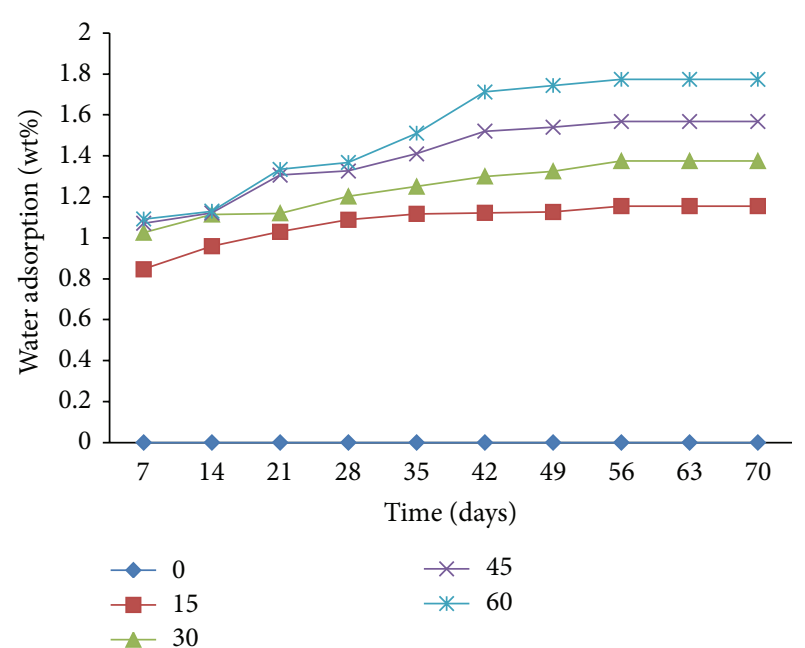

FIGURE 5: Water absorption in the presence of MA-g-PE.

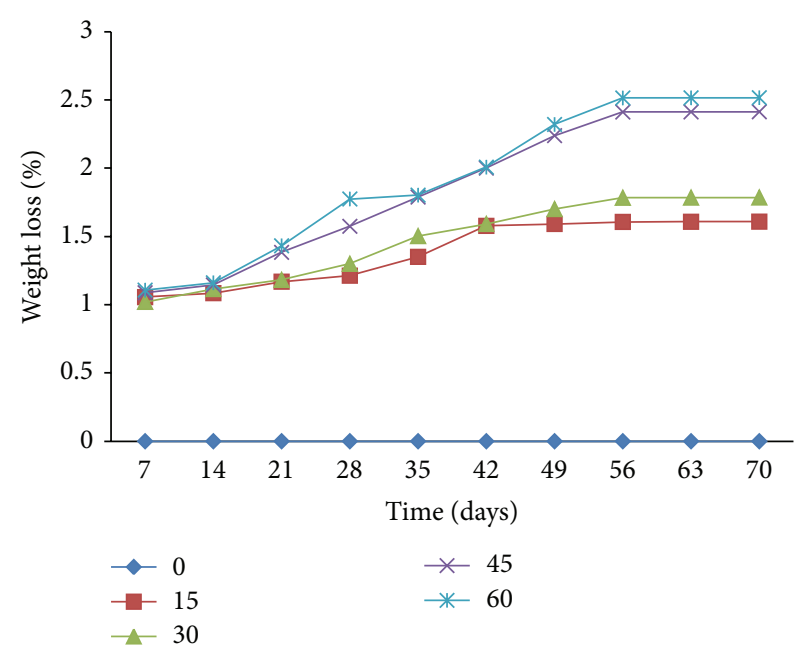

FIgURE 6: Weight loss at different RPIF Loadings.

being absorbed [15]. In the presence of compatibilizer, MA-g$\mathrm{PE}$ in this study, a reduction in the amount of water absorbed by the RPIF was observed when compared with compatibilizer free composites. This reduction in water absorption is attributed to some of the hydroxyl groups reacting with acid anhydride of MA-g-PE to form ester linkages, with the resultant decrease in water absorption values. Similar to our findings, Rohani et al. [16] who studied thermoplastic Sago/Kenaf filled low density polyethylene reported that the water absorption indices of the composites increased with increase in thermoplastic Sago/Kenaf fibre loading and with the addition of compatibilizer, MA-g-PE, water uptake was found to decrease.

3.3. Soil Burial Test. The natural soil burial test is well known to be a slow process. However, it is interesting to know that the soil burial test reflects real-life situation better than any other test. The weight loss of polymer blend samples during biodegradation in soil shows the amount of degradation in

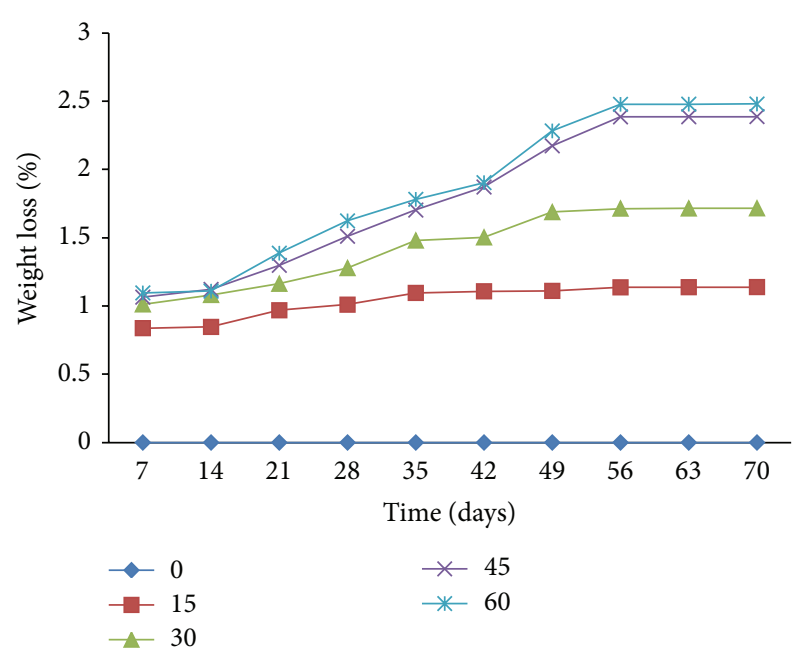

FIGURE 7: Weight loss in the presence of MA-g-PE.

natural environment with soil microorganism attacking the samples. The influence of soil burial duration on weight loss of the composites is illustrated graphically in Figures 6 and 7. It can be seen that the weight loss of the composites increases with increase in filler content as well as burial time. Blends with low amount of filler content have lower weight loss. This suggests that the microorganisms feed on the filler and create pores in the polymer matrix. In the presence of MA$\mathrm{g}-\mathrm{PE}$, the weight loss at each corresponding filler content in the blend was lower when compared to composites without MA-g-PE. This might be due to the same effects earlier advanced. After 70 days of exposure to soil environment, the blends were found to have reduced in size and weight and become hard and fragile. However, both uncompatibilized and compatibilized PE composites experienced continuous weight loss as the soil burial period progressed.

To improve the investigation about weight loss behavior of the blends, weight loss of the samples was measured after every seven days. This was taken as the weight of the sample on each seventh day minus the preceding weight of the sample prior to seven days and the results obtained are illustrated graphically in Figures 8 and 9. It is observed from the figures that most of the samples experienced an initial increase in weight loss during the first 21 days and a decrease in the next 7 days. The composites showed an increase in the next 7 days, a drop in the sixth seven days, and an increase again in the next 7 days. After a decrease in weight loss in the next 7 days, a gradual decrease in weight loss was observed during the last 14 days of soil burial period.

\section{Conclusion}

The blending of RPIF with HDPE has been synthesized successfully through melt blending using an extruder. MAg-PE was used as a compatibilizer. The results presented indicate that it is possible to improve the properties of biofibre reinforced HDPE through compatibilization. Compatibilized blends have superior properties over uncompatibilized 


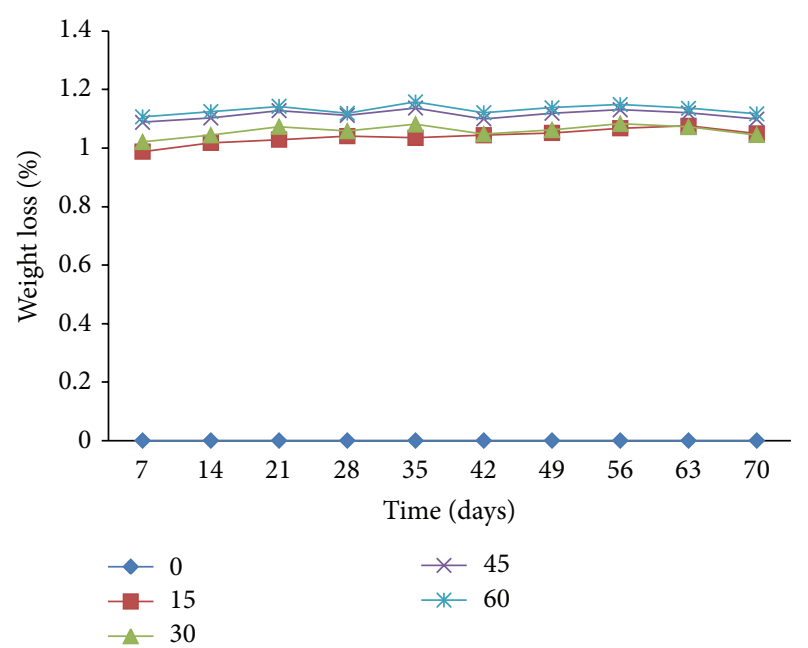

FIGURE 8: Weight loss after every 7 days at different RPIF Loading.

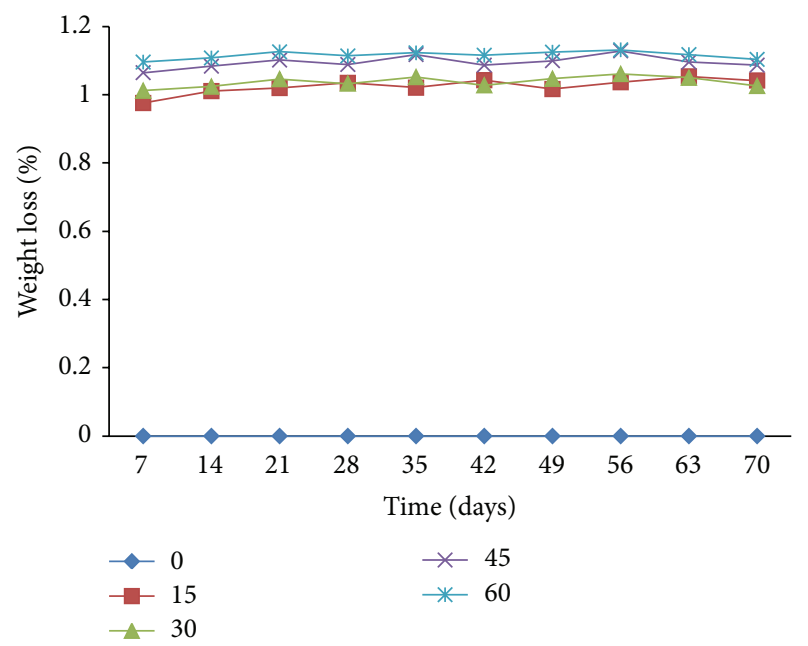

FIgURE 9: Weight loss after every 7 days in the presence of MA-g-PE.

blends due to improved adhesion and enhanced polar interactions at the fibre/matrix interface. The blends are noticeably more biodegradable than neat HDPE when subjected to natural soil environment. The study has established that blending with RPIF has enhanced the biodegradability of HDPE.

\section{References}

[1] M. Pracella, M. M.-U. Haque, and V. Alvarez, "Functionalization, compatibilization and properties of polyolefin composites with natural fibers," Polymers, vol. 2, no. 4, pp. 554-574, 2010.

[2] A. K. Bledzki and J. Gassan, "Composites reinforced with cellulose based fibres," Progress in Polymer Science, vol. 24, no. 2, pp. 221-274, 1999.

[3] A. S. Singha and V. K. Thakur, "Fabrication of Hibiscus Sabdariffa fibre reinforced polymer composites," Iranian Polymer Journal, vol. 17, no. 7, pp. 541-553, 2008.

[4] Optimat Ltd., MERL Ltd., "Wood plastic composites studytechnologies and U.K. market opportunities," Tech. Rep., 2003.
[5] K. Van De Velde and P. Kiekens, "Effect of flax/PP panel process parameters on resulting composite properties," Journal of Thermoplastic Composite Materials, vol. 16, no. 5, pp. 413-431, 2003.

[6] B. S. Kaith, A. S. Singha, and S. Kalia, "Grafting MMA onto flax under the influence of microwave radiation and the use of flax-g-poly(MMA) in preparing PF composites," Autex Research Journal, vol. 7, no. 2, pp. 119-129, 2007.

[7] D. De, D. De, and B. Adhikari, “The effect of grass fiber filler on curing characteristics and mechanical properties of natural rubber," Polymers for Advanced Technologies, vol. 15, no. 12, pp. 708-715, 2004

[8] S. K. Najafi, M. Tajvidi, and M. Chaharmahli, "Long-term water uptake behavior of lignocellulosic-high density polyethylene composites," Journal of Applied Polymer Science, vol. 102, no. 4, pp. 3907-3911, 2006.

[9] S.-T. Lim, "Effect of starch granule size on physical properties of starch-filled polyethylene film," Biotechnology Progress, vol. 8, no. 1, pp. 51-57, 1992.

[10] J. S. Peanasky, J. M. Long, and R. P. Wool, "Percolation effects in degradable polyethylene-starch blends," Journal of Polymer Science B, vol. 29, no. 5, pp. 565-579, 1991.

[11] D. Zuchowska, R. Steller, and W. Meissner, "Structure and properties of degradable polyolefin-starch blends," Polymer Degradation and Stability, vol. 60, no. 2-3, pp. 471-480, 1998.

[12] I. Kaur and N. Gautam, "Starch grafted polyethylene evincing biodegradation behavior," Malaysian Polymer Journal, vol. 5, no. 1, pp. 26-38, 2010.

[13] Z. Guohua, L. Ya, F. Cuilan, Z. Min, Z. Caiqiong, and C. Zongdao, "Water resistance, mechanical properties and biodegradability of methylated-cornstarch/poly(vinyl alcohol) blend film," Polymer Degradation and Stability, vol. 91, no. 4, pp. 703-711, 2006.

[14] N. Sombatsompop, C. Yotinwattanakumtorn, and C. Thongpin, "Influence of type and concentration of maleic anhydride grafted polypropylene and impact modifiers on mechanical properties of PP/wood sawdust composites," Journal of Applied Polymer Science, vol. 97, no. 2, pp. 475-484, 2005.

[15] G. Kale, T. Kijchavengkul, R. Auras, M. Rubino, S. E. Selke, and S. P. Singh, "Compostability of bioplastic packaging materials: an overview," Macromolecular Bioscience, vol. 7, no. 3, pp. 255277, 2007.

[16] R. A. Majid, H. Ismail, and R. M. Taib, "Effects of polyethyleneg-maleic anhydride on properties of low density polyethylene/ thermoplastic sago starch reinforced kenaf fibre composites," Iranian Polymer Journal, vol. 19, no. 7, pp. 501-510, 2010. 

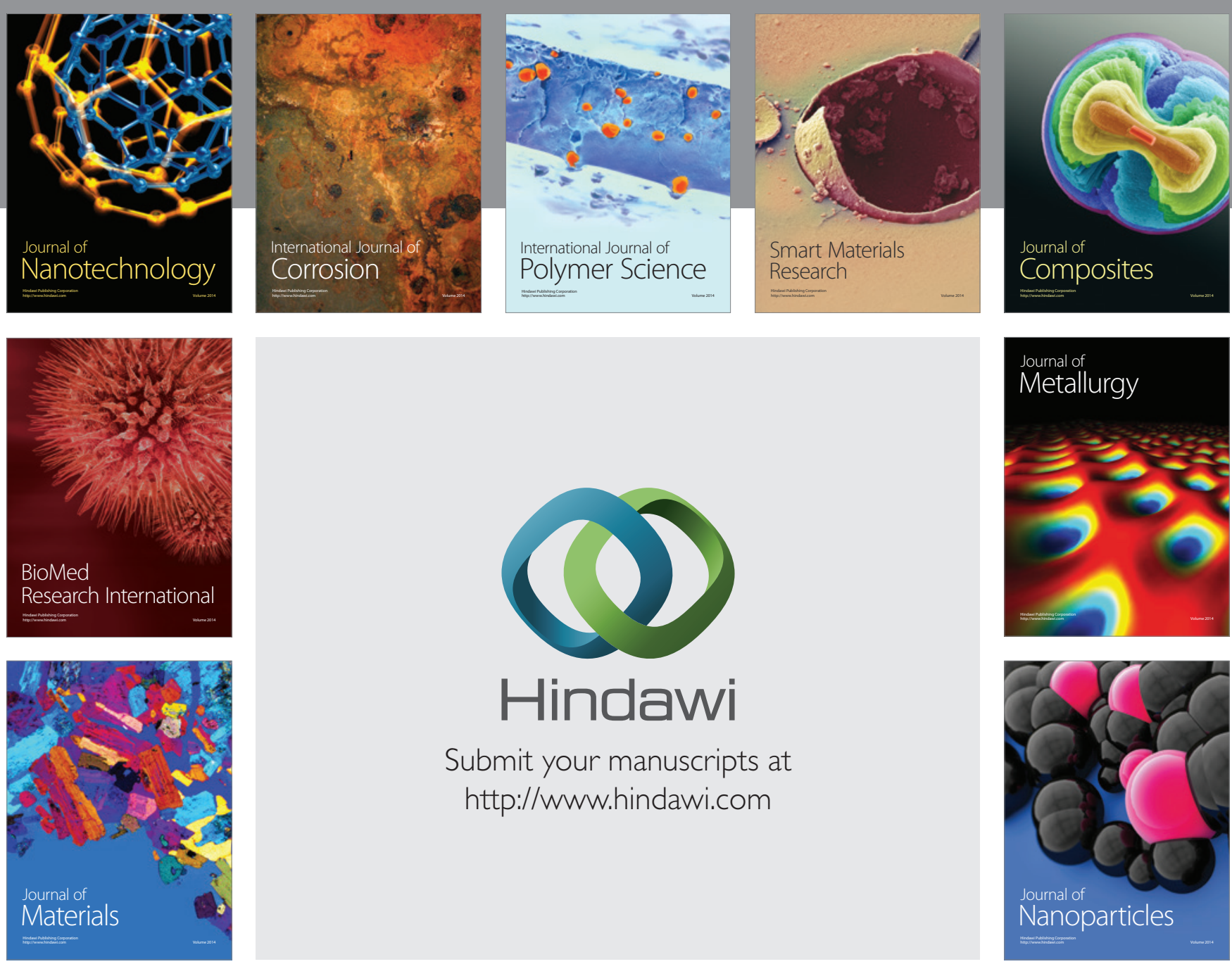

Submit your manuscripts at http://www.hindawi.com
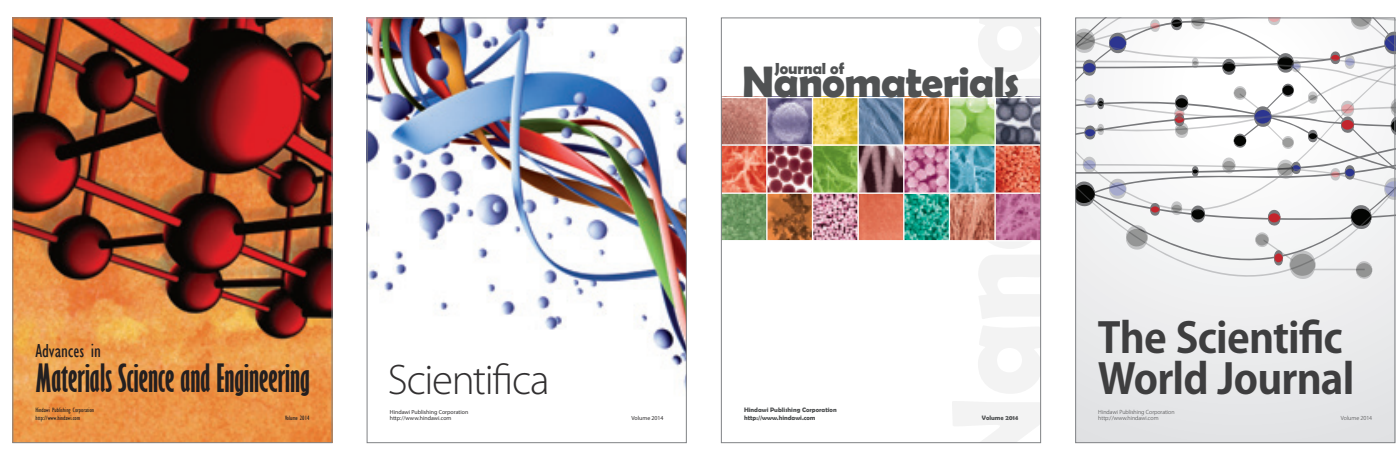

\section{The Scientific World Journal}
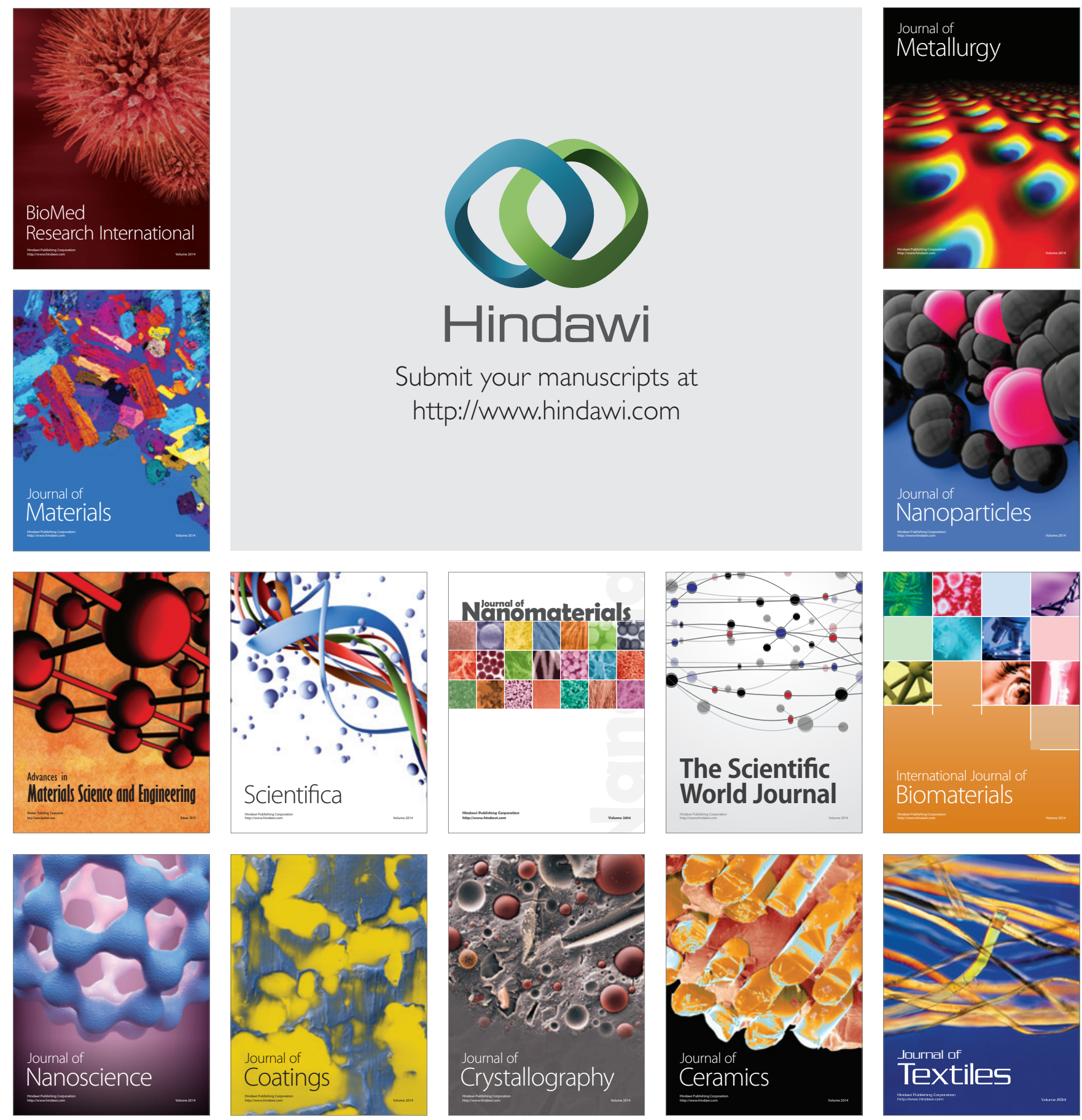